
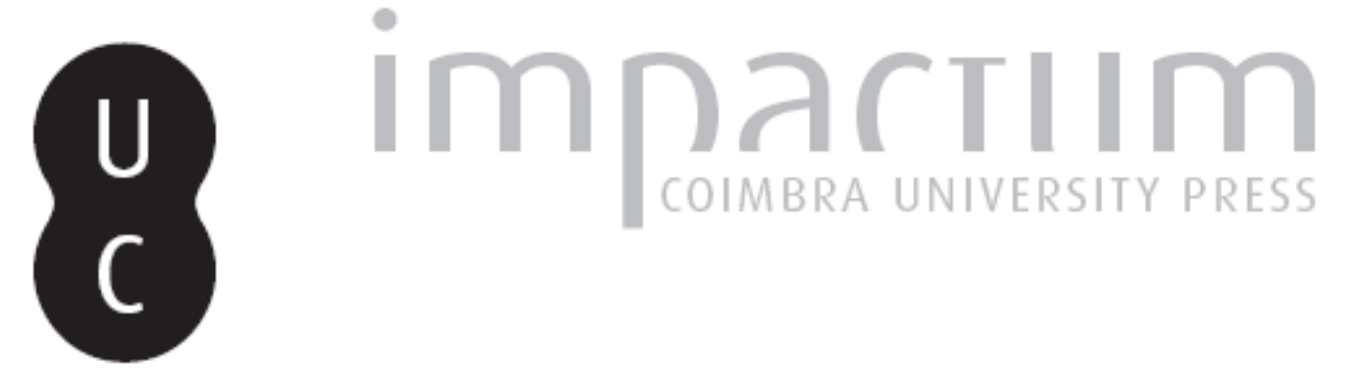

\title{
Arquitetura e educação: o exemplo de uma escola de educação infantil em Uberlândia
}

\author{
Autor(es): $\quad$ Santos, Elza Cristina
}

Publicado por: Editorial do Departamento de Arquitetura

URL

persistente:

URI:http://hdl.handle.net/10316.2/37263

DOI:

DOI:http://dx.doi.org/10.14195/1647-8681_4_12

Accessed : $\quad$ 26-Apr-2023 07:16:59

A navegação consulta e descarregamento dos títulos inseridos nas Bibliotecas Digitais UC Digitalis, UC Pombalina e UC Impactum, pressupõem a aceitação plena e sem reservas dos Termos e Condições de Uso destas Bibliotecas Digitais, disponíveis em https://digitalis.uc.pt/pt-pt/termos.

Conforme exposto nos referidos Termos e Condições de Uso, o descarregamento de títulos de acesso restrito requer uma licença válida de autorização devendo o utilizador aceder ao(s) documento(s) a partir de um endereço de IP da instituição detentora da supramencionada licença.

Ao utilizador é apenas permitido o descarregamento para uso pessoal, pelo que o emprego do(s) título(s) descarregado(s) para outro fim, designadamente comercial, carece de autorização do respetivo autor ou editor da obra.

Na medida em que todas as obras da UC Digitalis se encontram protegidas pelo Código do Direito de Autor e Direitos Conexos e demais legislação aplicável, toda a cópia, parcial ou total, deste documento, nos casos em que é legalmente admitida, deverá conter ou fazer-se acompanhar por este aviso.

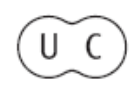




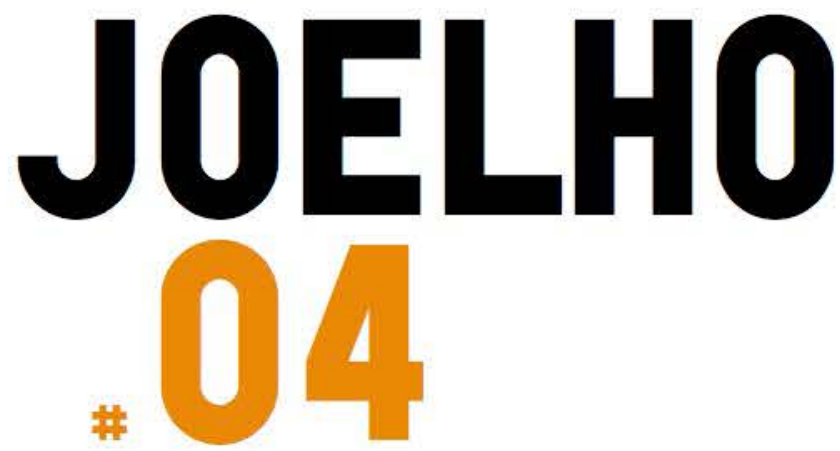

\section{ENSINAR PELO PROJETO \\ TEACHING THROUGH DESIGN}

\section{Coordenaçẫo:}

Paulo Providência

Gonçalo Canto Moniz

Alexandre Alves Costa Juan Domingo Santos Florian Beigel Philip Christou Elizabeth Hatz David Leatherbarrow Andrew Clancy Colm Moore Michael McGarry Willemijn Wilms Floet

Exposição TAPE 20Ir-12 


\section{Elza Cristina Santos Ãrquitetura e educação: - exemplo de unna escolla de educação infíñàii emp Ūberlâñndia}

Este trabalho apresenta o exercício projetual e as reflexões teóricas de uma pesquisa de doutorado na área de projeto de arquitetura, cuja investigação teve como ponto de partida o interesse em estudar aspectos gerais que envolvem o tema arquitetura e educação e, por objetivo, compreender o espaço escolar, contextualizado e delimitado nas escolas que atendem a crianças de zero a seis anos de idade e elaborar um projeto de arquitetura para uma escola de educação infantil, que apresente soluções com qualidade espacial, lúdica e ambiental necessárias à aprendizagem e ao desenvolvimento infantil.

Embora haja muitos estudos sobre a importância da dimensão espacial das atividades relacionadas à educação, este assunto ainda não foi esgotado; sendo assim, colocou-se em questão uma problemática envolvendo especialmente as escolas públicas de educação infantil: por que essas escolas não oferecem espaços de qualidade eficientes e adequados à educação infantil, mesmo quando se percebe que existe uma relação de afinidade entre o projeto pedagógico adotado e o edifício escolar?

Como resposta para esse questionamento, que também se apresenta como um problema arquitetônico, sugeriu-se que o edifício escolar, muito além de apresentar uma resposta espacial adequada para a realização e aplicação de um determinado projeto pedagógico, deveria considerar também o brincar como uma atividade importantíssima no processo de aprendizagem infantil, e deveria, portanto, apresentar soluções que contemplassem essa necessidade.
Delineado o problema e considerando o senso comum de que a criança aprende brincando, que para brincar é necessário espaço, e que os espaços de brincar das cidades estão se tornando espaços do automóvel e da violência, o espaço escolar torna-se ainda mais relevante, já que é nas escolas que as crianças passam a maior parte do seu tempo. É no espaço escolar que as crianças poderão recuperar os espaços de brincar perdidos nas cidades.

A partir desta reflexão, consideraram-se as hipóteses de que a maioria das escolas de educação infantil não apresenta espaços de qualidade para a educação das crianças; que a atividade lúdica é essencial no processo de desenvolvimento e aprendizagem infantil e que um espaço escolar complexo e polivalente se apresenta como um agente facilitador do processo de ensino-aprendizagem.

Embasada em autores como Hertzberger, Rapoport, Lynch, Tuan, Frago e Escolano e em pesquisas que envolvem esse tema, a investigação considerou conceitos importantes relativos à qualidade do espaço na arquitetura e à importância da percepção na relação criança-ambiente.

Dos estudos relacionados à qualidade dos espaços na arquitetura (Zevi, Hertzberger, Coelho Neto) ficou claro que é importante oferecer aos usuários espaços que determinem uma interação positiva entre eles e entre eles e a arquitetura. Verificou-se que essa interação pode ser facilitada e otimizada pela percepção sensorial (Hall, Tuan, Lynch, Rapport), já que os estímulos recebidos pelos sistemas receptores da 
visão, audição, olfato e tato intensificam a relação homem-ambiente, colaborando desta forma, na apreensão e identificação dos lugares pelas pessoas.

Os estudos do lúdico (Brougère, Huizinga, Kishimto, Bomtempo, Friedmann, Mazzilli, Tornquist) possibilitaram uma visão mais aprofundada da importância do brincar na vida das crianças e comprovaram a hipótese de que a atividade lúdica é essencial para o desenvolvimento e a aprendizagem infantil, pois estimula nas crianças a linguagem, o pensamento, a socialização, a exploração, a invenção, a motricidade, a imaginação e a fantasia.

Complementando esses estudos, as pesquisas de Frago e Escolano, Lima, Castro, Elali, Mazzilli, Bastianini, Chicco e Mela ajudaram na comprovação da hipótese de que um espaço escolar complexo e polivalente se apresenta como um agente facilitador do processo de ensino-aprendizagem.

Essa ideia fundamenta-se nos pressupostos teóricos da construção do conhecimento elaborados por Piaget, segundo o qual a pessoa aprende consigo mesma e vai construindo seu conhecimento a partir de interações com o ambiente. Essa construção começa desde o nascimento e se estende por toda a vida. Daí a importância dada aos lugares que recebem as crianças, visto que a inteligência delas pode ser afetada pela interação com o espaço, especialmente nos primeiros anos de vida. Essa experiência espacial deverá influenciar o processo de aprendizagem e o desenvolvimento infantil, tanto no aspecto físico quanto no aspecto sócioemocional e intelectual.

Tais reflexões demonstram que o brincar e o espaço são fundamentais na formação das crianças. $\bigcirc$ espaço propicia a oportunidade de brincar, e o brincar livremente num determinado espaço facilita à criança o desenvolvimento do movimento, da inteligência e das relações sociais e afetivas, e permite o reconhecimento e a conquista do espaço.

A hipótese de que a maioria dos estabelecimentos destinados às escolas de educação infantil não apresentam espaços de qualidade para as crianças de 0 a 6 anos foi comprovada nas visitas às escolas de educação infantil públicas da cidade de Uberlândia. Nessas visitas, verificou-se que as potencialidades dos espaços não foram exploradas, e que a arquitetura era monótona, desinteressante, fria e padronizadora, tanto na forma quanto na organização dos ambientes, oferecendo às crianças poucas oportunidades de se envolverem em atividades lúdicas, ou seja, poucas oportunidades para uma educação interativa de qualidade, adequada à educação infantil.

A partir da comprovação dessas hipóteses chegou-se a uma ideia central, síntese das diversas discussões abordadas na pesquisa, que abrange conceitos de humanização da arquitetura baseados na hipótese de projetos fundamentados em princípios arquitetônicos. Esses conceitos: acolhimento, complexidade, polivalência, transparência e ludicidade fundamentaram a tese de que a dimensão lúdica dos espaços escolares - aquelas qualidades que os tornam mais interativos, atraentes, estimulantes e acolhedores - contribui para um ambiente que promove a relação entre seus usuários, corresponde

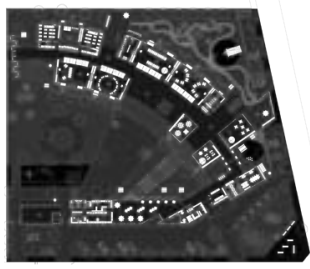

1. Layout espaços internos.
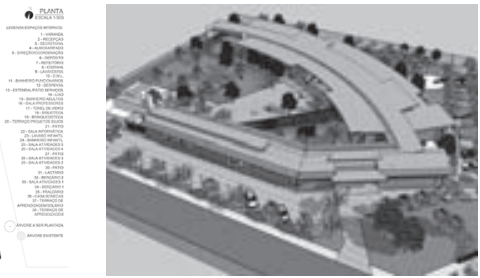

2. Perspectiva geral. às necessidades da criança, participa e interage com a construção de seu conhecimento.

Esses conceitos também determinaram as diretrizes, ou seja, os parâmetros projetuais (Nair, Fielding \& Lackney) que definiram a essência do projeto arquitetônico (fig.1, 2, 3) da escola proposta: integração com a comunidade (fig.4); desenho aberto/interação com o meio natural; escola como uma pequena comunidade de aprendizagem; iluminação natural e ventilação natural (fig.5, 6); ambientes acolhedores (fig.7); circulação como um passeio de aprendizagem (fig.8); adaptabilidade/flexibilidade/variedade (fig.9, 10, 11); transparência e supervisão passiva (fig.12); arquitetura que ensina/sustentabilidade; espaços externos e incentivos lúdicos (fig.13); materiais, texturas e cores como elementos de identidade.

$\bigcirc$ processo de projeto iniciou-se com os estudos teóricos e desenvolveu-se após a verificação da legislação pertinente às escolas de educação infantil e a análise do programa de necessidades, das características climáticas da região e do sítio e, ainda, da consideração da proposição mencionada acima.

Essa proposição, que seria a resposta para o questionamento inicial da pesquisa, conduziu a reflexão para alguns fatores que pudessem agir como catalisadores na interpretação dos dados obtidos inicialmente, fugindo, desta forma, de soluções previsíveis que serviriam somente para a satisfação óbvia das necessidades do programa para uma escola de educação infantil.

Assim, desde o princípio, foram considerados importantes e como itens de projeto os seguintes fatores:

- valorização da esquina, estabelecendo um diálogo entre o edifício e o entorno (fig.14);

- utilização de uma tipologia que configurasse uma "praça", ponto de encontro e socialização de seus usuários, onde o caráter lúdico do espaço pode ser revelado (fig.15);

- respeito às características originais e preservação de árvores existentes, elementos de grande importância para a arquitetura e para o microclima da região.

A partir daí, o processo de projeto foi naturalmente se desenvolvendo, sempre apoiado sobre a sustentação teórica que norteou a pesquisa e que assegurou a qualidade da solução desejada. Cumpre ressaltar que o ato de projetar não é um processo linear que se desenvolve a partir de um conceito até chegar a uma solução final. Projetos (desenhos) também podem levar a formulação de conceitos (ideias) e vice-versa. Existe uma relação mútua entre eles, onde todos os aspectos devem ser analisados e ajustados a fim de se chegar a uma solução que satisfaça todos os requisitos exigidos e todas as expectativas.

Dessa forma, antes mesmo da ideia central ser totalmente desenvolvida, alguns desenhos foram elaborados e neles verificouse que já estavam contidos alguns aspectos teóricos importantes apontados nos conceitos estabelecidos.

A pesquisa não teve como propósito estabelecer normas para a elaboração de projetos de escolas para a educação infantil.

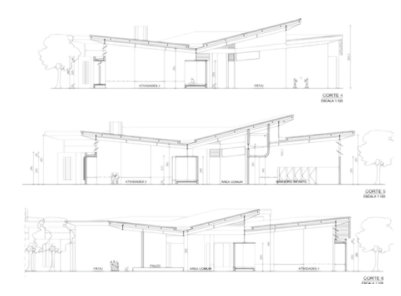

3. Cortes. 

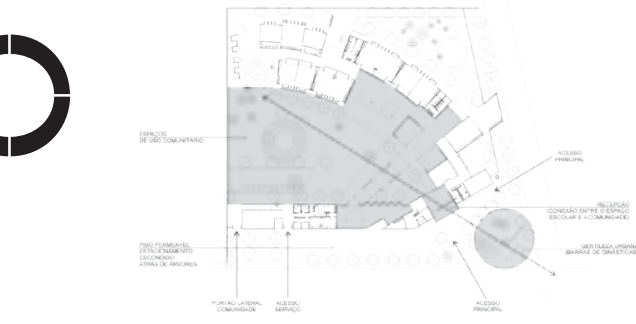

4. Espaço escolar integrado ao espaço urbano.

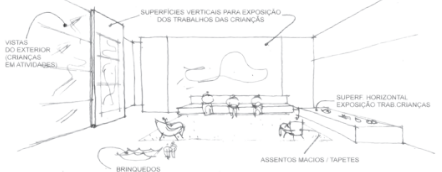

7. Ambientes acolhedores: recepção.

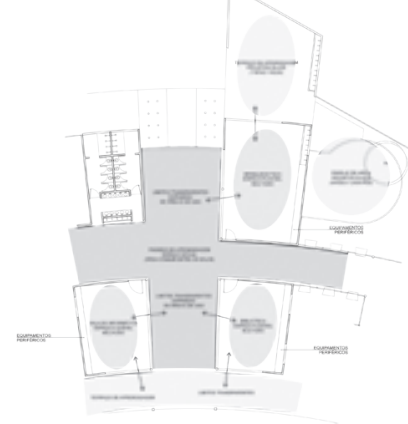

10. Adaptabilidade/flexibilidade/ variedade: salas especiais.

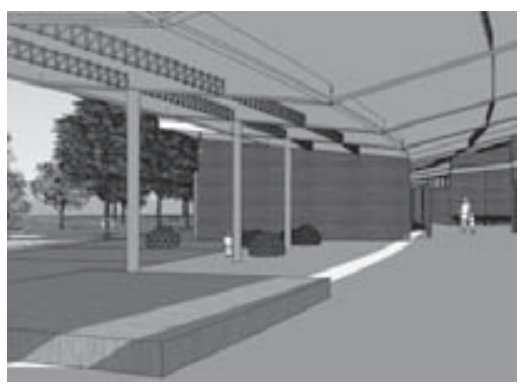

13. Espaços externos e incentivos lúdicos: pátio coberto.

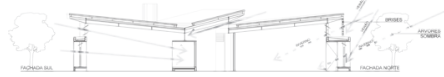

5. lluminação natural.

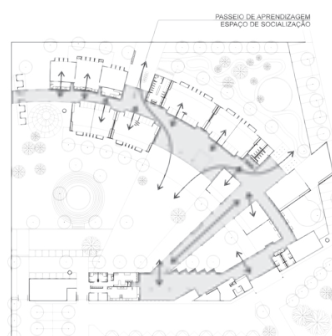

8. Circulação com um passeio de aprendizagem.

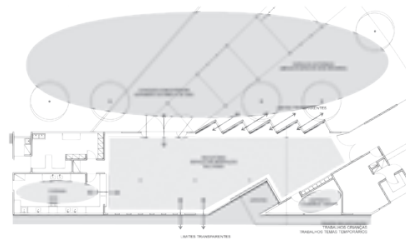

11. Adaptabilidade/flexibilidade/ variedade: refeitório.

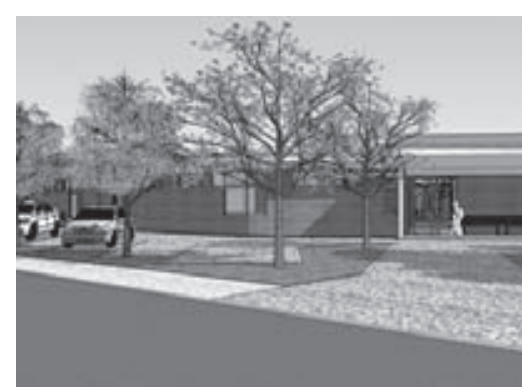

14. Valorização da esquina.

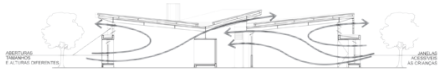

6. Ventilação natural.

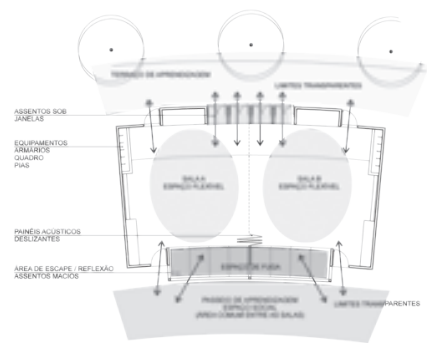

9. Adaptabilidade/flexibilidade/variedade: salas de atividades.

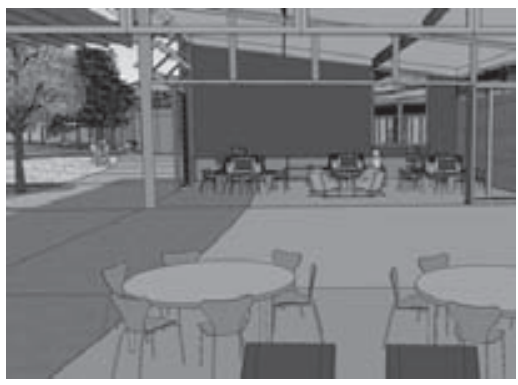

12. Visibilidade entre os ambientes da escola.

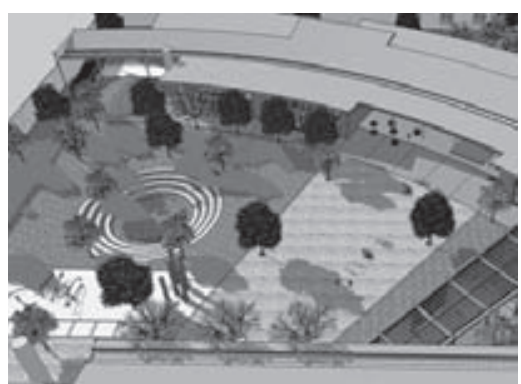

15. Praça central. 
Entretanto, o projeto desta escola, definido segundo essas diretrizes, complementa a tese e sua finalidade é exemplificar e refletir os conceitos abordados, possibilitando um caminho para o aprofundamento do conhecimento da arquitetura.

Algumas das diretrizes determinadas nesse processo projetual consideraram contribuições de pesquisas e de projetos analisados, outras são apenas a confirmação das sugestões contidas na legislação e na literatura pertinentes às escolas de educação infantil, outras ainda representam uma tentativa de solucionar os problemas detectados nos estudos de caso e, finalmente, algumas delas representam uma tentativa de acrescentar inovações na área.

De qualquer modo, é importante lembrar que essas diretrizes e esses conceitos - acolhimento, complexidade, polivalência, transparência e ludicidade - podem ser úteis quando se deseja elaborar projetos de escolas cujo foco é a aprendizagem, sobretudo a aprendizagem lúdica, que considera tanto o brincar quanto o espaço, elementos fundamentais para o desenvolvimento infantil. Escolas que apresentam espaços com essas qualidades podem se tornar fontes de estímulos, de aprendizados e inter-relacionamentos.

Finalmente, recomenda-se, como continuidade da pesquisa, aplicar esses conceitos na elaboração de projetos com outros usos e outras tipologias e soluções arquitetônicas, sobretudo quando a humanização dos espaços se faz necessária.

\section{Referências Bibliográficas}

Bastianini, A. M.; Chicco, E.; Mela, A. (2002). O espaço e a criança: em busca de segurança e aventura; in, Del Rio, V., Duarte, C. R.; Rheingantz, P. A. Projeto do lugar: colaboração entre psicologia, arquitetura e urbanismo. Rio de Janeiro: Contra capa livraria / PROARO.

Bomtempo, E., Hussein, C. L., Zamberlan, M. A. T. (1986). Psicologia do brinquedo: aspectos teóricos e metodológicos. São Paulo: Nova Estela: Editora da Universidade de São Paulo.

Brouère, G. (1998). Jogo e educação; trad. Patrícia C. Ramos. Porto Alegre: Artes médicas.

Castro, F. F. M.. (2000). Relação espaço-aprendizado: uma análise do ambiente pré escolar. Dissertação de Mestrado, FAU/USP.

Coelho Neto, J. T. (1979). A construção do sentido na arquitetura. São Paulo: Editora perspectiva S. A.

Elali, G. A. (2002). Ambientes para educação infantil: um quebra cabeça? Tese de doutorado. São Paulo: FAUUSP.
Frago, A. V., Escolano, A. (2001). Currículo, espaço e subjetividade: a arquitetura como programa. Rio de Janeiro: DP\&A Editora.

Friedmann, A. (1996). Brincar: crescer e aprender O resgate do jogo infantil. São Paulo: Moderna.

Hall, E. T. (1989). A dimensão oculta; tradução de Sonia Coutinho. Rio de Janeiro: F. Alves.

Hertzberger, H. (1996). Lições de Arquitetura. São Paulo: Martins Fontes.

-

Huizinga, J. (1980). Homo Ludens: o jogo como elemento da cultura; tradução de João Paulo Monteiro. São Paulo: Perspectiva.

-

Kishimoto, T. M. (Org). (2002). Jogo, brinquedo, brincadeira e a educação. São Paulo: Cortez.

-

Lima, M. W. S. (1995). Arquitetura e educação. São Paulo: Studio Nobel.

Lynch, K. (1997). Imagem da cidade; tradução Jefferson Luiz Camargo. São Paulo: Martins Fontes.
Mazzilli, C. De T. S. (2003). Arquitetura lúdica. Tese de doutorado. São Paulo: FAUUSP.

Nair, P., Fielding, R., Lackney, J. (2009). The language of school design: Design patterns for 21st century schools. Disponível em Designshare.com.

Piaget, J. A epistemologia genética. Tradução de Nathanael C. Caixeiro, traduzido do original francês L'épistémologie génétique, Paris: Presses Universitaires de France, 1970.

-

Rapoport, A. (1978). Aspectos humanos de la forma urbana. Barcelona: Gustavo Gili.

-

Tornquist, J. (2008). Colory luz: teoria y práctica. Barcelona: Gustavo Gili.

-

Tuan, Y. (1983). Espaço e lugar: a perspectiva da experiência. São Paulo: Difel.

Zevi, B. (1994). Saber ver a arquitetura. $4^{\mathrm{a}} \mathrm{ed}$. Tradução de Maria Isabel Gaspar, Gaetan Martins de Oliveira. São Paulo: Martins Fontes. 